Sylwester Jędrzejewski SDB

\title{
Wspomnienie o ks. prof. Andrzeju Strusie SDB
}

12 czerwca 2005 odszedł do Pana ks. prof. Andrzej Strus SDB - w 67 roku życia, 50 ślubów zakonnych i 41 kapłaństwa.

Urodził się 19 kwietnia 1938 w Strusach na Podlasiu. Nowicjat w Towarzystwie Salezjańskim, studia i praktykę pedagogiczną odbył w latach 1954-1964. W 1964 roku przyjął święcenia kapłańskie. Zrazu posługiwał w duszpasterstwie w Łodzi, po czym odbył studia biblijne w KUL. Przełożeni zakonni dostrzegli w nim człowieka zdolnego i pracowitego, rokującego nadzieję na dobrą pracę na niwie naukowej. Dlatego w roku 1969 ks. Andrzej został skierowany na specjalistyczne studia biblijne na Biblicum w Rzymie (licencjat nauk biblijnych Topos ,, la joie de la nature” dans le Psaumes), które uwieńczył doktoratem u L. Alonso Schökela: Nomen-Omen. Poétique sonore dans le Pentateuque et les Livres historiques w roku 1976. Po powrocie do kraju prowadził pracę dydaktyczną w seminarium salezjańskim w Kutnie Woźniakowie. Wkrótce wrócił jednak do pracy na polu biblijnym w Rzymie w Università Pontificia Salesiana. W tym czasie pełnił też swoją biblijną posługę w Salezjańskim Instytucie św. Pawła w Cremisan k. Betlejem w Izraelu, w Lubumbashi w Kongo, w Istituto Internazionale Don Bosco w Turynie. W 1997 roku osiadł na stałe w Rzymie.

Jego życie naukowe pełne było różnego rodzaju aktywności. Pisał publikacje książkowe i artykuły w uznanych periodykach biblijnych europejskich i polskich, redagował książki naukowe i popularyzujące Biblię, chętnie włączał się w różne inicjatywy naukowo-pastoralne, których owocem były publikacje przybliżające Pismo Święte. Nie tracił kontaktu z krajem ojczystym, pisząc zarówno w publikatorach salezjańskich („Nostra”), jak i w ogólnopolskich („Collectanea Theologica”, „Studia Theologica Varsaviensia”, „Ateneum Kapłańskie”, „Seminare”, „Tygodnik Powszechny”). Publikował także na łamach „Ruchu Biblijnego i Liturgicznego”.

Chętnie przyjmował propozycje wykładów w kraju i za granicą. Jego związek z Polską i polską biblistyką był zresztą przemożny. Jako zaszczyt poczytywał sobie zaproszenie do współpracy w inicjatywie warszawskiego ośrodka biblijnego wydania serii Wprowadzenie w myśl $i$ wezwanie ksiąg biblijnych. Jego wkładem jest tam opracowanie Księgi Psalmów w tomie 
7 (Pieśni Izraela), Księgi Lamentacji w tomie 8 (Prorocy Izraela) i Księgi Barucha w tomie 5 (Wielki świat starotestamentalnych proroków).

W ostatnim czasie zajmował się zagadnieniami relacji judaizmu i chrześcijaństwa, redagując m.in. Tra giudaismo e cristianesimo. Qumran, giudeocristiani, Roma 1995. W tym duchu zaangażował się w obronę i poparcie dla idei upamiętnienia żydowskich ofiar bestialstwa niemieckich nazistów w miejscowości Kocki, w parafii Nowojelnia na Białorusi. Wspomagał miejscowego proboszcza w staraniach o zachowanie zbiorowej mogiły zamordowanych w 1942 roku Żydów, mężczyzn, kobiet i dzieci, oraz wzniesionego na miejscu ich kaźni pomnika.

Prawdziwa jego pasją w ostatnich latach życia stała się archeologia biblijna. Prowadził badania i warsztaty archeologiczne w Ziemi Świętej dla studentów UPS. We współpracy z prof. M. Piccirillo z Jerozolimy oraz archeologami angielskimi, izraelskimi i polskimi prowadził badania archeologiczne w regionie Szefeli oraz w Beth Gemal (Khirbet Jiljil) i Beth Shemesh (wespół z prof. prof. J.-B. Humbertem, archeologiem z Jerozolimy, restauratorem starożytnych monumentów, G. Mantellą z Londynu i J. Gozdalikiem, architektem-archeologiem z Warszawy). Rezultaty zostały opublikowane w kilku dziełach: Kfar Gamla in the Shephela. On the traces of ST. Stephen and Gamaliel, Jerusalem (w języku włoskim i hebrajskim); Khirbet Fattir-Bet Gamal. Two Ancient Jewish and Christian Sites in Israel, Roma 2003; Bet Gemal. Pathway to the Tradition of Saints Stephen and Gamaliel, Roma 2000; ntyb lmswrt hqdwsym stpn wgmly'l (w języku angielskim i hebrajskim), Roma 2001. Uczestniczył w powstaniu unikatowej Archaeological Encyclopedia of the Holy Land, New York-London 2001 pod redakcją A. Negeva i S. Gibsona.

Dużo swoich sił, zresztą ograniczonych przez słabość organizmu, poświęcił ks. prof. Andrzej Strus jednoczeniu salezjanów-biblistów z całego świata w organizacji Associazione Biblica Salesiana (ABS), której przez pewien okres także przewodniczył. Jeszcze na przełomie grudnia 2004 i stycznia 2005 organizowaliśmy razem w Krakowie odbywający się co pięć lat Kongres Stowarzyszenia. Ks. Andrzej jako prezydent Stowarzyszenia w sposób niezwykle dynamiczny zgromadził na nim biblistów z 16 krajów Europy, Azji i Ameryki. Udzielał się aktywnie także w Associazione Biblisti Italiani (ABI). Z radością przyjął informację o powstaniu Stowarzyszenia Biblistów Polskich i zgłosił do niego swój akces. Przypominam sobie, jak prosto z samolotu, lądując w Warszawie, przyjechał na doroczny Zjazd Biblistów Polskich do Lublina, żeby być razem ze swoimi kolegami-biblistami i podzielić się z nimi rzymskimi nowościami biblijnymi.

Ks. prof. Andrzej Strus SDB zapisał się w naszej pamięci jako człowiek bardzo życzliwy, wręcz dobrotliwy. Niezwykle przystępny dla młodych adep- 
tów wiedzy biblijnej, kochający swoje zgromadzenie, otwarty na każdego człowieka, zwłaszcza młodych studentów. W ostatnich latach choroba onkologiczna nie pozwoliła mu już na normalną aktywność. Niemniej jednak pełen był różnych planów i nadziei. Kiedy wrócił do Rzymu z Kongresu Biblistów Salezjańskich w Krakowie w styczniu 2005, choroba odezwała się ze szczególną intensywnością. Nic już nie pomogły zabiegi lekarzy. Mimo to pojawił się kilkakrotnie w transmisji telewizyjnej z Rzymu w czasie, gdy przeżywał swoje ostatnie dni na tej ziemi Ojciec Święty Jan Paweł II. Mówił o swojej bliskości z cierpiącym Ojcem Świętym i o szczególnym umiłowaniu przez tego papieża młodych ludzi. Owa bliskość miała szczególny wymiar, sam przecież był już ogromnie cierpiący. Odszedł do Pana, którego umiłował, w dniu 12 czerwca 2005 roku. Pożegnaliśmy go zrazu w Rzymie na uniwersytecie, gdzie w czasie liturgii pogrzebowej kazanie wygłosił dziekan Wydziału Teologicznego UPS ks. prof. G. Zevini SDB, a potem w Warszawie, w bazylice Serca Jezusowego na Pradze. Liturgii pogrzebowej przewodniczył kolega ks. Andrzeja z okresu studiów rzymskich abp M. Gołębiewski, zaś w imieniu polskich biblistów i współbraci salezjanów pożegnał zmarłego ks. Andrzeja ks. prof. dr hab. R. Rubinkiewicz SDB.

\section{Dorobek naukowy ks. prof. Andrzeja Strusa SDB}

Rozprawa doktorska: Nomen-Omen. Poétique sonore dans le Pentateuque et les Livres historiques, Pontificio Istituto Biblico, Facoltà Biblica, Roma 1976

\section{PuBLIKACJE KSIĄżKOWE}

Nomen-Omen. Stylistique des noms propres dans le Pentateuque, Rome 1978 (Analecta Biblica, 82)

Bet Gemal. Pathway to the Tradition of Saints Stephen and Gamaliel, Roma 2000

ntyb lmswrt hqdwsym stpn wgmly'l (ed. angielska i hebrajska), Roma 2001

Khirbet Fattir - Bet Gemal. Two Acient Jewish and Christian Sites in Israel, Roma 2003

\section{KSIĄŻKI POD JEGO REDAKCJĄ}

Bosco T., Spetniony sen, tłum. i adapat. pod red. A. Strusa, Rzym 1979.

Schöekel L. A., Stowo natchnione, tłum. A. Malawski, red. nauk. A. Strus, Kraków 1983 Maria nella sua terra, a cura di A. Strus, Cremisan 1989

Inculturazione e formazione salesiana. Dossier dell'Incontro di Roma, 12-17 settembre 1983, a cura di A. Amato e A. Strus, Roma 1984

Tra giudaismo e cristianesimo. Qumran, giudeocristiani, a cura di A. Strus, Roma 1995

Dummodo Christus annuntietur. Studi in onore del prof. Jozef Heriban, a cura di A. Strus, R. Blatnicky, Roma 1998

La tua Parola e luce sul mio cammino. Atti del 4. convegno mondiale ABS su Parola di Dio e formazione salesiana, Cremisan, 23 ago.-2 sett. 1999, Roma 2000

Parola di Dio e comunita religiosa, a cura di A. Strus e R. Vicent, Torino 2003

Strus A., Picca J., La Bibbia nel suo ambiente. Introduzione alla Sacra Scrittura, Roma 2003 


\section{PUBLIKACJE W DRUKACH ZWARTYCH}

Śpiewajcie nam pieśni Syjonu. Księga Psalmów, [w:] Wprowadzenie w myśl i wezwanie ksiąg biblijnych, t. 7: Pieśni Izraela, Warszawa 1988

Wstań, wołaj po nocach! Księga Lamentacji, [w:] Wprowadzenie w myśl i wezwanie ksiag biblijnych, t. 8: Prorocy Izraela, Warszawa 1989

Morte e vita dell'aldilà nell'Antico Testamento, [w:] Il mistero dell'aldila, a cura di E. Quarello, Roma 1979, s. 37-55 (Biblioteca di scienze religiose, 21)

Una catechesi sull'Esodo. Il Deuteronomio, [w:] Un Dio che libera. Studi sull'Antico Testamento, a cura di M. Cimosa e F. Mosetto, Torino 1982, s. 162-178

"Géraséniens" dans la tradition synoptique. Jalon topographique ou omen onomastique?, [w:] El mistero de la Palabra, Valencia-Madrid 1983, s. 283-301

Interprétation des noms propres dans les oracles contre les nations, [w:] Congress Volume. Salamanca 1983, Leiden 1985, s. 272-285 (Supplements to Vetus Testamentum, 36)

Biblijne podstawy tytułu 'Wspomożycielka' nadawanego Matce Zbawiciela, [w:] Maryja Wspomożenie Wiernych. Studium dogmatyczno-historyczne, praca zbiorowa pod red. S. Prusia, Warszawa 1986, s. 15-92.

Wiara w macierzyńska pomoc Maryi w okresie poprzedzajacym sobór efeski, [w:] Maryja Wspomożenie Wiernych. Studium dogmatyczno-historyczne, praca zbiorowa pod red. S. Prusia, Warszawa 1986, s. 93-121

Santuari mariani in Palestina nel periodo bizantino, [w:] Maria nella sua terra, a cura di A. Strus, Cremisan 1989, s. 35-66

Lettura dei testi biblici nell'Enciclica «Redemptoris Mater», [w:] Maria nella sua terra, a cura di A. Strus, Cremisan 1989, s. 149-156

L'educazione alla fede nei Profeti, [w:] AA.VV., Parola di Dio e evangelizzazione dei giovani. Atti del III Convegno Mondiale dell'ABS, Roma 1994, s. 75-108

Satana nel mondo biblico tra reale e immaginario, [w:] La sfida di Beelzebul. Complessità psichica o possessione diabolica?, a cura di E. Fizzotti, Roma 1995, s. 31-54

Ottimismo e gioia, [w:] Parola di Dio e spirito salesiano. Ricerca sulla dimensione biblica delle costituzioni della famiglia salesiana, a cura di J. Bartolome e F. Perrenchio, Torino 1996, s. 283-296

Christiani di origine giudaica: un'esperienza sepolta? Dati archeologici ed apocrifi, [w:] Tra giudaismo e cristianesimo. Qumran, giudeocristiani, a cura di A. Strus, Roma 1995, s. 87-115

«Plenitudo temporis». Cronologia della salvezza in Gal 4, 4, [w:] Dummodo Christus annuntietur. Studi in onore del prof. Jozef Heriban, a cura di A. Strus, R. Blatnicky, Roma 1998, ss. 57-84

An ancient Jewish Calendar in Jewish-Christian Apocriphon on St. Stephen, [w:] Proceedings of the Twelfth World Congress of Jewish Studies. Jerusalem, July 29-August 5, 1997, proceedings ed. R. Margolin, Jerusalem 1999

Calendric Aspects in a Recently Discovered Jewish-Christian Apocryphon, [w:] Proceedings of the Twelfth World Congress of Jewish Studies. Jerusalem, July 29-August 5, 1997, proceedings ed. R. Margolin, Jerusalem 1999

Transformations sociales et religieuses en Judée au temps des Hasmonéens (IIème. Ier siècles av. J. C.) d'après un témoignage archéologique, [w:] Science and technology for the safeguard of cultural heritage in the Mediterranean Basin. Proceedings, ed. A. Guarino, Paris 2000, s. 203-211

Wyznanie win i nadzieja wygnańców. Księga Barucha, [w:] Wprowadzenie w myśl i wezwanie Ksiag biblijnych, t. 5: Wielki świat starotestamentalnych proroków, Warszawa 2001², s. 130-150

Il Corpo del Signore - il cibo della vita (Gv 6, 24-59), [w:] L'Eucaristia nel vissuto dei giovani, a cura di P. Carlotti, M. Maritano, Roma 2002, s. 157-175 (Biblioteca di Scienze Religiose, 175)

Fattir (Khirbet), [w:] Archaeological encyclopedia of the Holy Land, ed. by A. Negev and S. Gibson, New York-London 2001 
Jiljil (Khirbet el-; Beit Jimal), [w:] Archaeological encyclopedia of the Holy Land, ed. by A. Negev and S. Gibson, New York-London 2001

Deuteronomio - un libro per comprendere una comunità, [w:] Parola di Dio e comunita religiosa, a cura di A. Strus e R. Vicent, Torino 2003, s. 31-45

Bet Gemal and the Byzantine Tradition regarding St. Stephen, [w:] Ecce ascendimus Jerosolymam (Lc 18,31). Miscellanea di studi offerti per il 75. dello Studentato teologico salesiano in Terra Santa e il centenario dell Ispettoria salesiana del Medio Oriente, a cura di F. Mosetto, Roma 2003, s. 399-418 (Biblioteca di Scienze Religiose, 184)

Je passerai mon anneau à ta narine (Is 37,29). Isaïe et l'impèrialisme de l'Assyrie, [w:] Foi et politique dans la Bible. Actes des premières Journées Bibliques de Lubumbashi. 25-27 février 2003, Lubumbashi 2004, s. 37-59

\section{ARTYKUŁY}

Mc 9,33-37. Problema dell'autenticità e dell'interpretazione, „Rivista Biblica Italiana” 20 (1972), s. 589-619

Funkcja obrazu w przekazie biblijnym: obraz winnicy w Iz 5,1-7, „Studia Theologica Varsaviensia” 15 (1977), s. 25-53

Etymologie des noms propres dans Gen 29,32-30,24: valeurs littéraires et fonctionnelles, „Salesianum” 40 (1978), s. 57-72

La poétique sonore des récits de la Génèse, „Biblica” 60 (1979), s. 1-22

Kochanowskiego interpretacja Psalmów, „W Drodze” 35 (1980), s. 25-31

Salmo 122: Canto al nombre de Jerusalén, "Biblica” 61 (1980) 234-250

Pucka Katecheza o Abrahamu. Post 12-25, „Katecheza” 3 (1981), s. $52-59$

Geremia - Profeta di preghiera e di intercessione, „Salesianum” 43 (1981), s. 531-550

Cristo, Liberatore dell'uomo nella catechesi di Pietro, secondo Mc 5,1-20, „Salesianum” 44 (1982), s. 35-60

Una tomba del primo periodo romano sul Monte Oliveto, „Liber Annuus” 32 (1982), s. $335-354$

Jeden Bóg - jedno Słowo - jedno Pismo, „Ateneum Kapłańskie” 442 (1982), s. 414-428

Jeremiasz - prorok modlitwy za swój naród, „Collectanea Theologica” 52 (1982), s. 35-56

Magnificat - hymnem Matki ubogich, „Seminare” 6 (1983), s. 315-330

Legenda, tradycja i historia o zaśnięciu i wniebowzięciu NMP, „Ruch Biblijny i Liturgiczny” 37 (1984), s. 127-139

Historia Józefa - „podręcznikiem” wychowania młodego Izraelity, „Seminare” 7 (1985), s. $5-27$

Una liberazione dall'alto. Rilettura dell'Esodo, „Parole di Vita” 2 (1986), s. 84-93

Rozwój proroctwa o Emmanuelu jako przykład hermeneutyki w Starym Testamencie, „Ruch Biblijny i Liturgiczny" 39 (1986), s. 197-211

La crypte de l'église bizantyne à Beit-Jimal, „Liber Annuus” 38 (1988), s. 277-285 s. $1-26$

Beit-Gemal può essere il luogo di sepoltura di Santo Stefano?, „Salesianum” 54 (1992),

Une installation agricole à 'Ain Fattir, „Revue Biblique” 99 (1992), s. 425-439

Una ricerca storica sulla Passione di Gesù e l'esegesi biblica oggi, „Salesianum” 55 (1993), s. $725-738$

La storia di Giuseppe Egiziano - esempio dell'educazione alla sapienza, „Parole di Vita” 40 (1995), s. 3-9

L'isopséphie des abréviations byzantines: une solution pour une inscription de Kh. Ain Fattir, „Révue Biblique” 102 (1995), s. 242-254

La Passione di Santo Stefano in due manoscritti greci, „Salesianum” 58 (1996), s. 21-61 
L'origine de l'apocryphe grec de la Passion de S. Etienne: à propos d'un texte des deux manuscrits récemment publiés, „Ephemerides Liturgicae” 113 (1998), s. 18-57

Una haggada familiare sulla passione e morte di S. Stefano Protomartire "Salesianum" 60 (1998), s. 81-96

\section{ARTYKUŁY POPULARNE}

Ja wierzę w Chrystusa, ,Tygodnik Powszechny” 1974

Abyście się wzajemnie miłowali, ,Tygodnik Powszechny” 1981

Medżugorie - miejsce spotkania Boga z ludźmi, „Tygodnik Powszechny” 1985

Prośmy o pokój dla Jerozolimy, „Tygodnik Powszechny” 1988

Il XXV dell'Istituto teologico salesiano di Lad, "L'Osservatore Romano" (9 kwietnia 1978)

200.000 polacchi per la Madonna di Różanystok, "Bollettino Salesiano” 1981

Tydzień duchowości salezjańskiej, „Nostra” 28 (1973), s. 2-5

Noc Narodzenia w Betlejem, „Nostra” 29 (1974), s. 60-62

Struktura życia zakonnego na Papieskim Uniwersytecie Salezjańskim, „Nostra” 30 (1975), s. 28-31

Teologia wobec aktualnych problemów Kościoła, „Nostra” 32 (1977), s. 25-33

Salezjańskie odczytanie znaków czasu. Refleksja pokapitulna, „Nostra” 4 (1978), s. 1-6

Aktualne walory katechezy patrystycznej, „Nostra” 10 (1978), s. 37-39

Duchowość ewangeliczna w formacji salezjańskiej, „Nostra” 3 (1979), s. 1-13

Pierwszy światowy Kongres Biblistów Salezjańskich, „Nostra” 12 (1982), s. 33-36

Kapituta Generalna XXII trwa..., „Nostra” 3 (1984), s. 1-8

Dobiegajac do mety, „Nostra” 5 (1984), s. 9-16

Mentorella - Madonna dwóch papieży, „Nostra” 11 (1984), s. 44-49

Medżugorie. Miejsce spotkania Boga z ludźmi, „Nostra” 5 (1985), s. 4-15; 6 (1985), s. 7-20 